\title{
A brief introduction to cone penetration testing (CPT) in frozen geomaterials
}

\author{
Adrian McCALLUM \\ University of the Sunshine Coast, Maroochydore, Queensland, Australia \\ E-mail: amccallu@usc.edu.au
}

\begin{abstract}
The cone penetration test has been successfully used to classify soil for $\sim 100$ years. However, it has received only limited contemporary use in frozen geomaterials. The historical and contemporary use of the cone penetration test in various frozen geomaterials is considered here and contemporary data from recent work in polar snow are examined. It is probable that many material physical properties (e.g. density, strength and microstructure) can be obtained directly from cone penetration testing. It appears under-utilized as a contemporary scientific and engineering investigative tool in frozen geomaterials.
\end{abstract}

KEYWORDS: applied glaciology, glaciological instruments and methods, ice engineering, snow mechanics

\section{INTRODUCTION}

Cone penetration testing (CPT) has been used successfully for $\sim 100$ years to 'sound' soils to depth. The test is used for profiling soil layers and for deriving soil properties, such as density, shear strength, angle of internal friction and cohesion (Schaap and Föhn, 1987).

Although other penetrometers have proven successful in frozen geomaterials (e.g. Bader and others, 1939; Schneebeli and Johnson, 1998; Buteau and others, 2005), they have typically been either manually driven or capable of only limited depth penetration, thereby limiting the attainable data. For this reason, McCallum (2012) modified commercial hydraulically driven CPT equipment to conduct extensive testing in Antarctica, validating the use of commercially available friction-sleeve equipped cone penetrometers in polar snow, terrestrial ice and sea ice.

This paper examines the historical and contemporary use of CPT in frozen geomaterials. Data that can be obtained from CPT are briefly discussed and the potential that CPT offers for determining shallow $(<10 \mathrm{~m})$ in situ physical properties of frozen geomaterials for both scientific and engineering purposes is considered. Before examining the specific utility of CPT, a brief review of other penetrative instruments is presented for completeness.

\section{Alternative penetration tests}

The Swiss rammsonde has been used to test snow hardness for many years. It was developed in 1936-37 by R. Haefeli (Haefeli, 1936), and consists of a rod with a conical tip, which is driven into the soil by means of a weight dropped onto the rod. The drop hammer is of a known weight and is dropped from a known height, allowing a ram resistance formula to be used to generate a ram hardness number, which describes the resistance in kilograms (Abele, 1963). Abele (1963) attempted to establish a relationship between ram hardness and unconfined compressive strength, but found a high degree of scatter. However, Mellor (1975) expressed sound reasons for seeking correlation between the two parameters, suggesting that a penetrative instrument (ostensibly measuring hardness) may provide a valid proxy for the strength of snow or other frozen geomaterials.
Bradley (1968) described the use of a snow resistograph, which was inserted to depth within the snowpack, rotated $90^{\circ}$ and then manually withdrawn. Resistance during withdrawal was measured by a spring in the handle of the resistograph, and thus a record of snow resistance as a function of depth could be generated. Bradley attempted to correlate the resistance data with a macroscale assessment of the snowpack compressive strength. However, although roughly equivalent data were generated, many unknowns in the conduct of the test meant that further development of both the instrument and means of interpretation was necessary.

The digital thermo-resistograph (DTR) built on Bradley's work and was developed by Dowd and Brown (1986). It used a 'semi-conductor strain gauge load cell with a 60 degree cone in the end of a probe'. A position sensor recorded the position of the probe, and the measured force divided by the projected area of the cone provided a measure of stress $(\mathrm{Pa})$. The development of this instrument appears to have been the precursor for the development of more refined instruments, such as the snow micro-penetrometer (SMP). Although another prototype was developed by Brown and Birkeland (1990), work on this was discontinued owing to durability problems.

The SMP, developed by Schneebeli and Johnson in 1997 (Schneebeli and Johnson, 1998), is perhaps the most mechanically advanced snow penetrative instrument currently used in assessing in situ snow strength. It uses an electric motor drive to push the conical instrument into the snow at a (largely) constant rate, and is the most expensive of the force-resistance probes (Floyer, 2006). The penetrometer was designed to be consistent with Fukue's thin-blade penetration tests (Fukue, 1977), which showed that an instrument of smaller dimensions may be more responsive to changes in material microstructure. The instrument has a cone diameter of $5 \mathrm{~mm}$, which is connected to a $3 \mathrm{~mm}$ drive rod. The SMP can be driven to depths of $\sim 4 \mathrm{~m}$, and generates data of penetration resistance (MPa) versus depth, with the ability to define snow layers down to $3 \mathrm{~mm}$ in thickness. Derivation of snow compressive strength from SMP data was described by Kronholm (2004). This research was based on work by Johnson and Schneebeli (1999), who performed a 


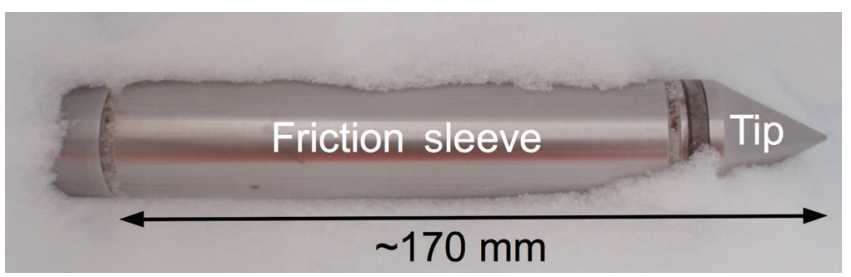

Fig. 1. Cone incorporating $35.6 \mathrm{~mm}$ diameter tip and $135 \mathrm{~mm}$ long cylindrical friction sleeve.

statistical analysis on the penetration of the penetrometer and derived an equation relating the angle of the SMP tip to the frictional coefficient of the snow grains. The SMP is a proven instrument for determining in situ snow strength; however, a number of considerations impact its use:

The penetration rate is not constant. Kronholm (2004) notes that operator weight is required to maintain the penetration of the cone tip when hard layers are encountered, causing either an increase or decrease in the penetration rate; thus the penetration rate cannot be assumed constant and any data interpretation must be cognizant of this.

The probe size means that if it is inserted to depth in frozen geomaterials it may not be sufficiently robust; a larger shaft and larger-diameter cone may be desirable. The SMP may be ineffective in penetrating hard polar snow (personal communication from O.P. Mattila, 2008, regarding the use of the SMP on Vestfonna ice cap, Svalbard).

Abele (1990) noted the development in the 1960s by the US Navy Civil Engineering Laboratory of a blunt-tipped rod, driven rapidly into snow via the hydraulic system of a small tractor. (This is similar to the operational concept of the CPT described in this paper.) Abele noted the in-principle desirable nature of such a test, because of its speed and simplicity, but also stated that the concept was not taken past the initial, apparently promising, experimental stage.

The SABRE probe, a portable, variable-speed, digital, round-tipped penetrometer was developed by Mackenzie and Payten (2002). It measures the force resistance of snow as well as snow temperature. It was designed for detecting snow layers, particularly with the purpose of identifying weak layers for the assessment of slope stability. The probe is novel in that, although it is manually inserted into the snow at variable rates, an internal accelerometer measures accelerations, and thus velocity and displacement, allowing a plot of penetrative force versus depth to be generated. The SABRE probe is light, portable, and easy to use (Floyer and Jamieson, 2006), but although it is valuable for snow slope assessment, its manual and thus variable insertion rate, to a limited depth, means that it is unsuitable for assessing the strength to depth of frozen geomaterials.

Floyer and Jamieson (2006) provided an update on digital penetrometer technology, discussing the SMP, the SABRE and the Capacitec probe. The Capacitec snow probe measures the dielectric permittivity of snow, an analogue for density. This probe is driven into the snow manually, providing unreliable rate information, and at this time does not provide a measure of strength or a proxy.

R. Alger (personal communication, 2008) used an electrically driven penetrometer mounted on the front of a tracked snow vehicle to obtain $>200$ profiles across the Antarctic continent in 2005, at depths to $1 \mathrm{~m}$. However, only limited data reduction or additional probe development is known to have occurred since then.

The nature of penetrative instruments historically used in assessing frozen geomaterials has briefly been examined. While significant development has occurred and the SMP is a proven instrument, the deficiencies outlined above limit its efficacy for the in situ strength assessment of frozen geomaterials to depth. Larger probes may be less responsive to snow microstructure; however, the ability to penetrate frozen geomaterials to depth at a constant rate using reliable, commercially proven equipment is attractive. The cone penetration test is now further described.

\section{THE CONE PENETRATION TEST (CPT)}

The cone penetration test (CPT) was developed in the Netherlands in the 1930s (Brouwer, 2007) and was initially known as the Dutch cone test. The test is used for profiling soil layers, and for deriving soil properties, such as density, shear strength, angle of internal friction and cohesion (Schaap and Föhn, 1987). The mechanical cone penetrometer has evolved over time to incorporate a sensor for measuring sleeve friction in the 1950s, and the development of an electric cone by Fugro in the 1960s, which was capable of measuring cone resistance and sleeve friction continuously during penetration (Schaap and Föhn, 1987).

\section{CPT equipment}

Cone penetration testing typically requires the following equipment:

A $35.6 \mathrm{~mm}$ diameter cylindrical steel cone, incorporating tip and friction sleeve: the cone tip measures resistance on the cone tip $(\mathrm{MPa})$, while axial friction $(\mathrm{MPa})$ is measured along the $135 \mathrm{~mm}$ long cylindrical friction sleeve (a standard cone is shown in Fig. 1).

Pushing equipment: hydraulic rams are typically used to force the cone (on the end of a rod string) into the ground at a standard rate of $20 \mathrm{~mm} \mathrm{~s}^{-1}$. Ram stroke may vary, but typically the cone is forced into the ground semicontinuously in a 'stop-start' manner in $1 \mathrm{~m}$ pushes.

Rods and clamp: driving force is transferred from the rams to the $36 \mathrm{~mm}$ diameter steel-alloy rods via a ballbearing-type clamp that slots into a frame attached to the top of the rams. The clamp can be manipulated to allow rods to be driven both downwards and upwards for rod and cone extraction. Maximum clamp capacity is typically $20 \mathrm{t}$ in either direction.

Data-recording equipment: this comprises a depthencoder to relate collected data to penetration depth, a data logger particular to the cone system in use, a laptop computer or proprietary recording device and the necessary cabling.

Typically, the CPT equipment is mounted on a heavy truck or trailer-rig, primarily to ensure that sufficient reaction force can be provided when driving into hard soils. However, equipment modified for use in the remote environments typical of frozen geomaterials needs to be relatively lightweight, transportable and preferably modular in nature. To address these requirements, McCallum (2014a) devised a 


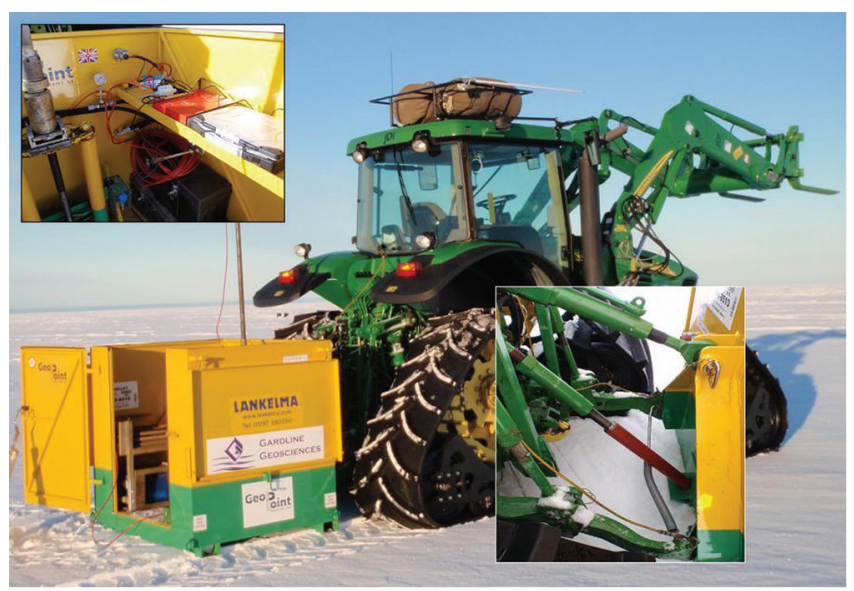

Fig. 2. CPT operating 'box' fitted to a BAS tractor, configured ready for use. Insets show rigid link installed and data-collection equipment.

'box' in which a CPT operator could stand, to contain CPT and ancillary equipment. This box was designed to fit on the three-point-hitch of a standard agricultural tractor, such as those used by the British Antarctic Survey (BAS) in Antarctica. McCallum's box, which is $1.7 \mathrm{~m}$ high, $1.45 \mathrm{~m}$ long and $1.35 \mathrm{~m}$ wide and weighs $\sim 1300 \mathrm{~kg}$ when loaded, is shown in Figure 2, fitted to a BAS tractor.

When conducting CPT in frozen geomaterials, tip resistances may exceed $40 \mathrm{MPa}$, resulting in reaction forces of perhaps $4 \mathrm{t}$ when using a standard $35.6 \mathrm{~mm}$ diameter cone. For this reason, McCallum's configuration (McCallum, 2014a) also utilized a heavy steel rod that provided a rigid link between the base of the box and the tractor. Even greater resistance to penetration could be measured by anchoring the box to the snow surface using a steel beam joining the box and screw anchors. However, this system was not found to be necessary in CPT in Antarctic firn (McCallum, 2014a). Smaller-diameter non-standard 'scientific' cones mobilize much less resistance during penetration and therefore may not need the reaction forces described above. However, smaller cones may not be robust enough to penetrate through hard frozen geomaterials, to depth, and a non-standard cone diameter complicates comparison with existing CPT datasets.

\section{CPT IN FROZEN GEOMATERIALS}

McCallum and others (2014) examined the viability of CPT as a tool for investigating sites in the Arctic, by reviewing the use of CPT in frozen geomaterials typical of polar regions. This is summarized below.

\section{Historical use of CPT}

\section{Permafrost}

Ladanyi (1976) examined the use of the electric penetrometer in assessing the time-dependent strength of frozen soil and later described the use of CPT for the design of piles in permafrost (Ladanyi, 1985). Ladanyi specifically noted the efficacy of the test in establishing the degree of ice bonding in offshore soils and outlined the derivation of material creep parameters and pile design loads. Ladanyi (2000) reviewed the performance of the CPT in ice and frozen soil and confirmed that the test is valuable for strength profiling and for

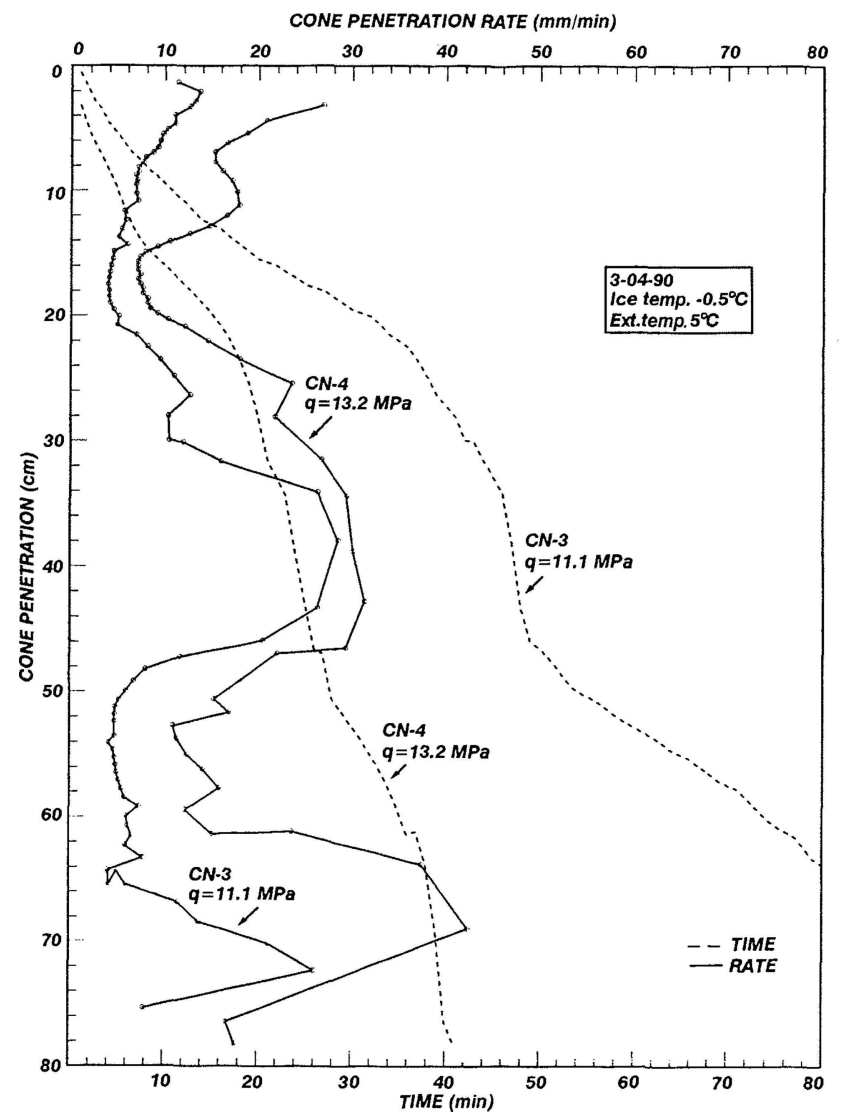

Fig. 3. Results of two parallel stress-controlled cone penetration tests through a sea-ice cover at Norris Point, Newfoundland, Canada, performed at constant cone pressures of 11.1 and 13.2 $\mathrm{MPa}$ and at an average ice temperature of $-0.1^{\circ} \mathrm{C}$, after Ladanyi and others (1991). (From Ladanyi, 1996, Borehole penetration and expansion devices for ice testing, Can. J. Civil Eng., 23, figure 1 (c) Canadian Science Publishing or its licensors. Reproduced with permission.)

creep and strength parameter determination within any given layer. He concluded by noting that the CPT is an excellent tool for frozen soil profiling and is particularly advantageous because pile design can be based directly on CPT results. Figure 3 (Ladanyi, 1996) shows results from parallel stresscontrolled cone penetration tests through sea ice.

Isaev and others (1995) stressed the importance of efficient methods of in situ investigation in permafrost, and described successful testing to depths of $20 \mathrm{~m}$ across an array of frozen soils: silt, clay and gravel. They also presented a derivation for estimating long-term pile resistance from in situ penetrative data and concluded that site assessment via static sounding is preferable because of time and cost efficiencies.

\section{Snow}

As described earlier, numerous mini-penetrometers have been employed for many years, primarily for avalanche research and the detection of weak layers (Floyer and Jamieson (2006) provide a review). However, there is only one historical instance of cone penetration testing in snow: Schaap and Föhn (1987) describe the use of a modified cone penetrometer that is manually driven into alpine snow. Figure 4 (Schaap and Föhn, 1987) shows a family plot of resistance data from three different tests located $\sim 1 \mathrm{~m}$ apart. 


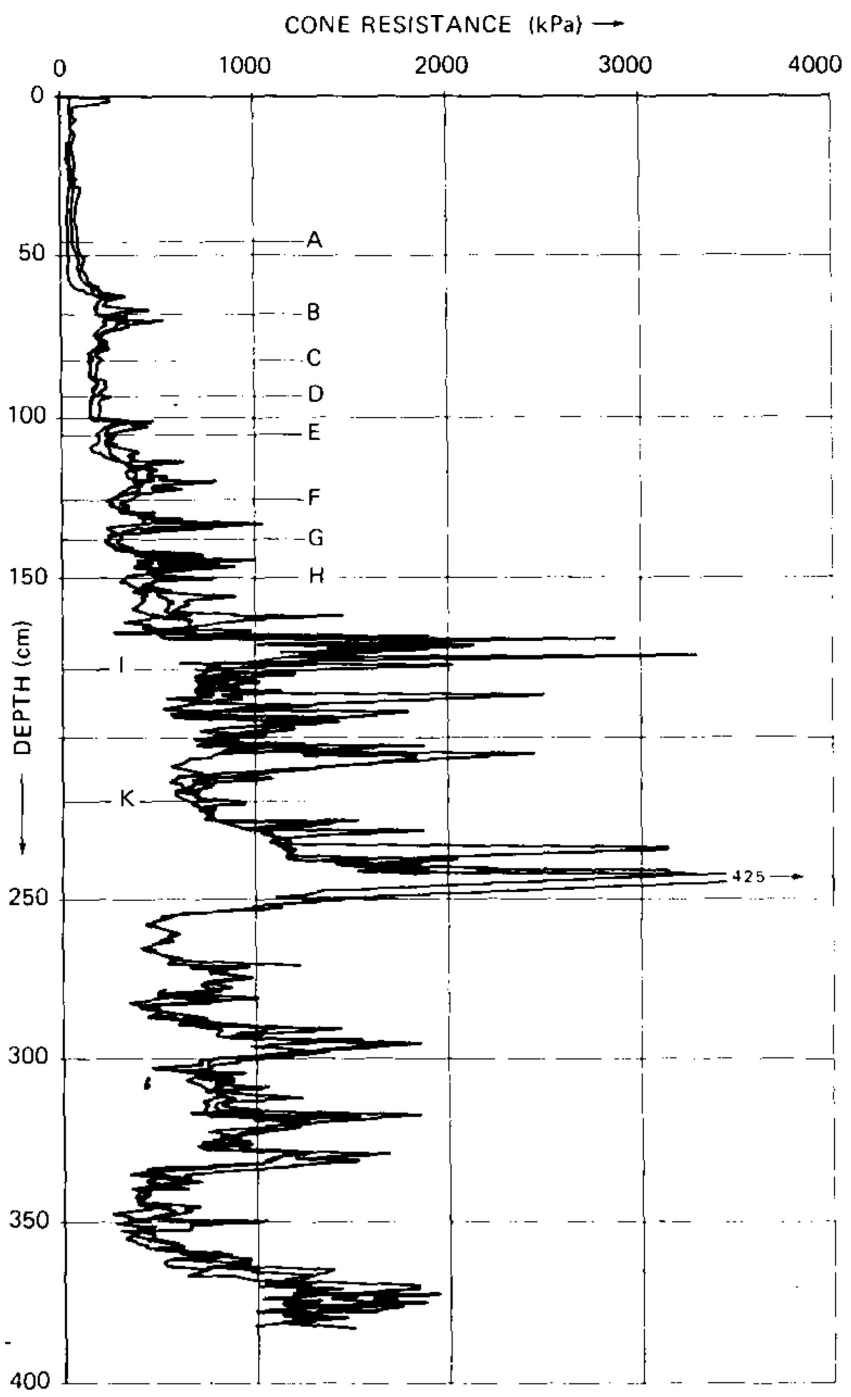

Fig. 4. Family plot of three cone resistance versus depth tests, located $\sim 1 \mathrm{~m}$ apart. (From Schaap and Föhn, 1987, Cone penetration testing in snow. Can. Geotech. J., 24(3), figure 9 @ 2008 Canadian Science Publishing or its licensors. Reproduced with permission.)

\section{Terrestrial ice}

There is little literature describing CPT in terrestrial ice. However, Ladanyi (1992) in examining methods for in situ testing of the strength and creep properties of ice, concluded that CPT largely addressed what he considered to be the three basic conditions for in situ ice testing:

Robust and mobile test equipment.

Simple to perform test.

Clear and easily interpretable test results.

Consistent with his work on permafrost, Ladanyi (1992) concluded that both a strength profile and creep parameters can be obtained from rate- or stress-controlled CPT in terrestrial ice.

\section{Sea ice}

In seeking an efficient device to quantify in situ sea-ice strength for the development of cold ocean resources, Ladanyi and others (1991) reported field tests evaluating CPT in sea ice. Tests were conducted in $1.14 \mathrm{~m}$ thick

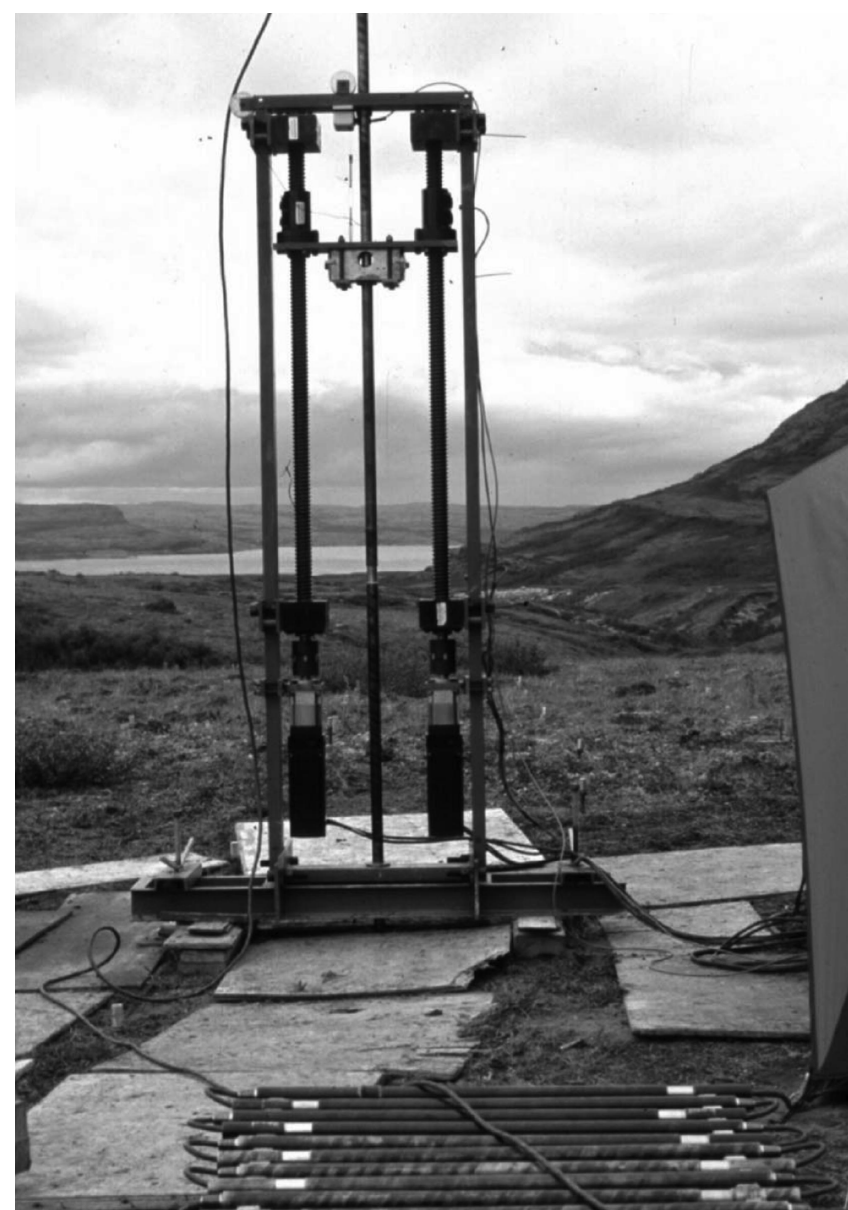

Fig. 5. Linear pushing system for rate-controlled CPT. (From Buteau and others, 2005, Rate-controlled cone penetration tests in permafrost, Can. Geotech. J., 42(1), figure 2 (C) 2008 Canadian Science Publishing or its licensors. Reproduced with permission.)

landfast sea ice, with a salinity of $\sim 1 \mathrm{ppt}$ and temperature just below $0^{\circ} \mathrm{C}$, at Norris Point, Newfoundland.

In this first-year ice, strengths determined via uniaxial compression tests were $\sim 2-3 \mathrm{MPa}$ and the ice was subsequently successfully tested using a standard Fugro electric cone penetrometer of $100 \mathrm{kN}$ capacity. Ladanyi and others (1991) explain that sufficient reaction force was supplied through the use of two anchors placed through the ice, with hydraulic power supplied by a gasoline-powered electrical power generator. By performing stress-controlled penetration tests, Ladanyi and others (1991) were able to determine creep parameters or the rate-dependent uniaxial compressive strength for the ice. Although they ultimately conclude that further work is necessary to quantify sea-ice strength via CPT, they identified favourable comparisons between CPTderived compressive strength and uniaxial compressive strength data, when corrected for both temperature and rate.

\section{Contemporary use of CPT}

\section{Permafrost}

Buteau and others (2005) described the development of ratecontrolled CPT apparatus and the conduct of rate-controlled penetration tests in permafrost. Their rugged and fieldportable device was used for stratigraphic profiling and to extract creep parameters in permafrost mounds derived from marine sediments (Fig. 5). They recorded tip resistances of up to $30 \mathrm{MPa}$ to depths exceeding $20 \mathrm{~m}$, and concluded that 


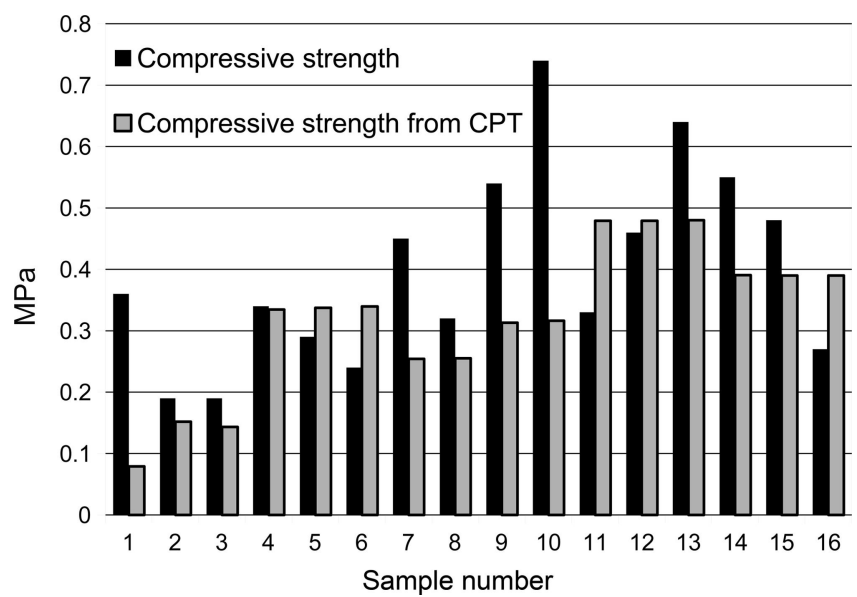

Fig. 6. Mean snow strength derived from CPT tip resistance differs by only $\sim 15 \%$ from strength derived via unconfined uniaxial compression testing. Data were not statistically different at the $95 \%$ confidence level (via unpaired $t$ test). Tests were both conducted at a penetration/compression rate of $20 \mathrm{~mm} \mathrm{~s}^{-1}$.

their equipment was useful for deriving material creep parameters and stratigraphy, particularly in remote locations.

In their compilation, Lunne and others (1997) describe the routine use of CPT in permafrost and confirm that it is a valuable site analysis tool in such material.

\section{Snow}

McCallum (2014a) conducted $\sim 100$ tests to depths of $10 \mathrm{~m}$ in snow on the Brunt Ice Shelf, where resistances were $>13 \mathrm{MPa}$ in compacted snow. He used the transportable CPT system mounted on the rear of an agricultural tractor described above. He states that three main determinants of snow's physical behaviour, its strength, density and microstructure, can potentially all be obtained via CPT. Snow strength derived from CPT was compared with unconfined uniaxial compression testing conducted at the same rate, and McCallum showed that mean strength values differed by only $\sim 15 \%$ and were not statistically different at the $95 \%$ confidence level (via unpaired $t$ test; see Fig. 6).

In addition, McCallum (2014b) presented a method for the direct estimation of snow shear strength from CPT data, and work continues to refine such relationships.

Thus far only limited CPT has been undertaken in polar snow. However, robust field-deployable CPT equipment is available, which can be used to obtain valuable site investigation data in such material.

\section{Terrestrial ice}

Aside from the penetration of ice layers (McCallum, 2014a), there are no known contemporary accounts of CPT in terrestrial ice. However, although it may be supposed that CPT in ice may prove difficult because of insufficient reaction force from the $\mathrm{CPT}$ rig, $\mathrm{CPT}$ tip resistance in ice appears no greater than resistances regularly encountered in non-frozen geomaterials (such as the examples given by Lunne and others, 1997).

\section{Sea ice}

McCallum (2012) successfully conducted rate-controlled CPT in multi-year fast ice. Testing was conducted to a depth of $\sim 1.2 \mathrm{~m}$ in ice of thickness $\sim 5 \mathrm{~m}$. However, the test was terminated when the CPT rods started bending at resistances

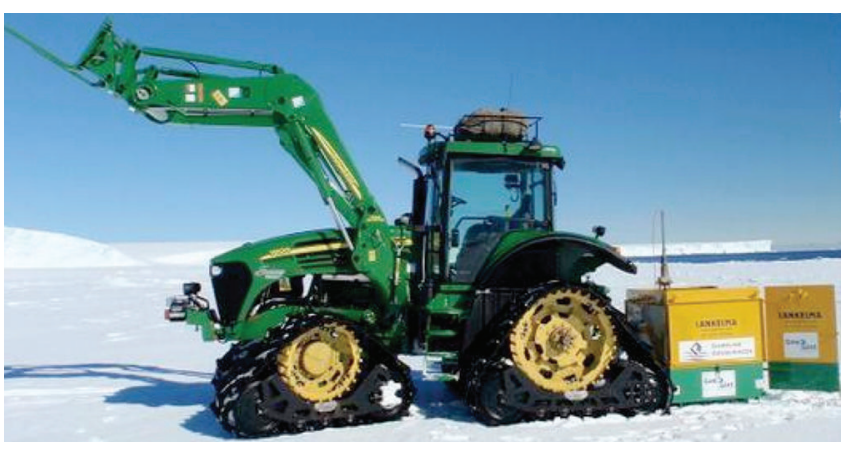

Fig. 7. Rate-controlled CPT $\left(20 \mathrm{~mm} \mathrm{~s}^{-1}\right)$ in Antarctic multi-year fast ice to depths exceeding $1 \mathrm{~m}$ using standard equipment (McCallum, 2012).

exceeding $40 \mathrm{MPa}$. Figure 7 shows the testing in progress and Figure 8 shows tip resistance versus depth obtained from one of these tests. As the strength of ice is ratedependent (Schulson and Duval, 2009) a faster testing rate might have resulted in decreased tip resistance and greater penetration depth.

Sea ice typically exhibits less strength than terrestrial ice, and testing has successfully been conducted in multi-year sea ice to resistances approaching $40 \mathrm{MPa}$ using standard CPT equipment.

\section{OBTAINABLE DATA}

Raw data obtained from CPT comprise:

(Tip) resistance to penetration, $q_{c}$, analogous to the confined or semi-confined compressive strength of the material (McCallum, 2014a).

Sleeve friction, $f_{\mathrm{s}}$, measured by the cylindrical friction sleeve located behind the cone tip.

Pore pressure, $u$, of the fluid (generally water but possibly air) within the pores of the penetrated medium.

Medium stratigraphy, evident as variations in both cone tip resistance and sleeve friction.

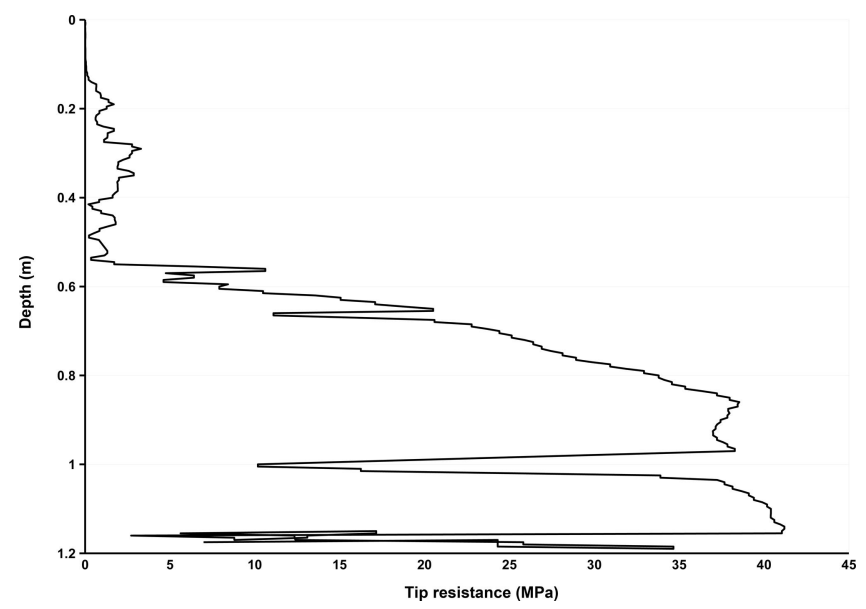

Fig. 8. Tip resistances recorded during successful CPT conducted in multi-year fast ice was $>40 \mathrm{MPa}$ (McCallum, 2012). Use of heavier equipment might have allowed greater penetration. 


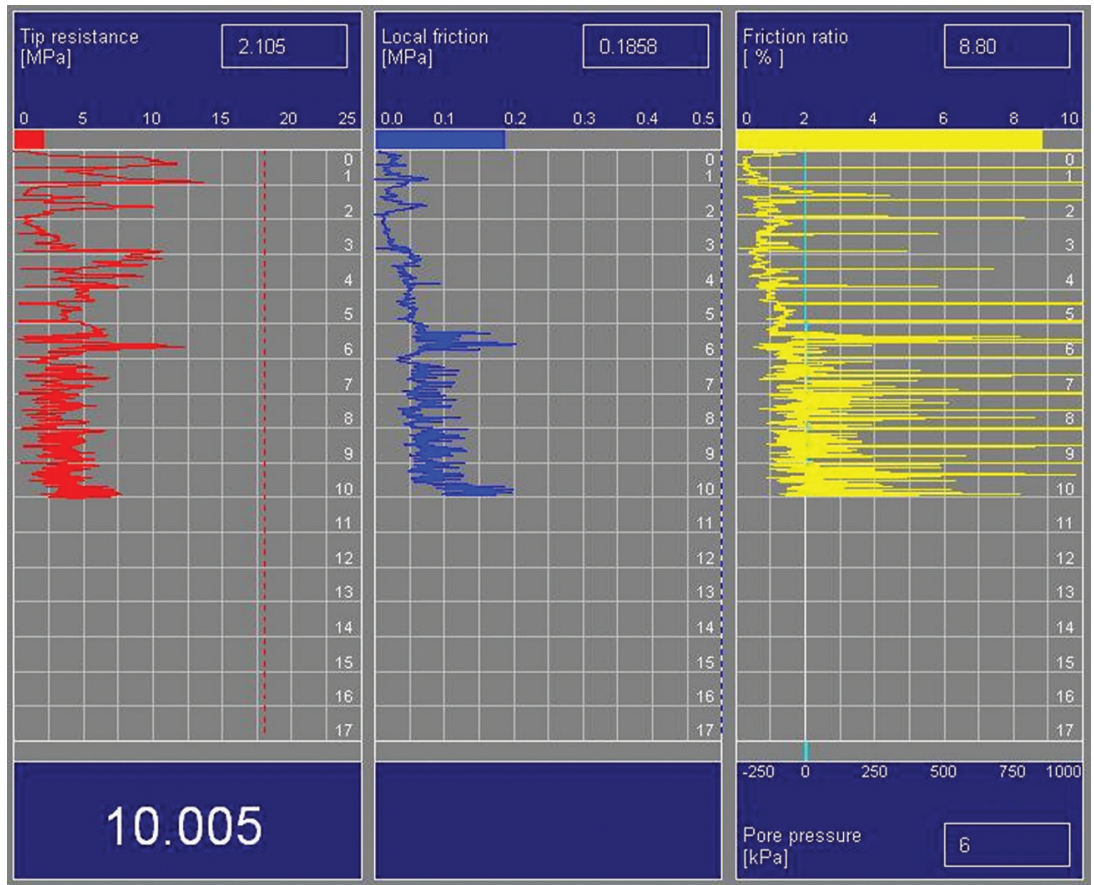

Fig. 9. Screen shot showing typical CPT data. Tip resistance is shown on the left in red, sleeve friction is shown in the middle in blue, and friction ratio $\left(R_{\mathrm{f}}=q_{\mathrm{c}} / f_{\mathrm{s}}\right)$ is shown on the right in yellow. Erroneous pore pressure reading $(6 \mathrm{kPa})$ is shown at bottom right. The test was to a depth of $\sim 10 \mathrm{~m}$. Excessive variation in the second half of the trace is because of increased frictional 'stick-slip' behaviour.

The friction ratio, $R_{\mathrm{f}}=q_{\mathrm{c}} / f_{\mathrm{s}}$, is also typically generated during the test and is used to determine material type or composition in tests in soil (Lunne and others, 1997). Figure 9 is a screen shot showing typical CPT data. Excessive variation in the second half of the trace is due to increased frictional 'stick-slip' behaviour. This can be reduced by fitting an oversized 'collar' behind the cone to reduce friction from the rod string.

Through analysis and manipulation of these initial data, additional physical parameters for the material can be estimated. Numerous accounts outline the data readily obtainable from CPT in snow, and presumably other frozen geomaterials where ice is the primary pore material (McCallum 2012, 2014a,b). Additional parameters that can possibly be obtained from CPT are (McCallum, 2012):

Density. McCallum (2012) observed that both tip resistance and sleeve friction vary with density in polar snow, and McCallum (2014c) postulated that after removal of increased frictional stress because of overburden, there is a significant relationship between sleeve-friction data obtained directly from CPT and snow density.

Shear strength. McCallum (2014b) discussed the derivation of material shear strength from CPT data, using the empirical relationships of Mellor (1975) to sum forces required to fracture and then compact material ahead of the cone; this relationship relies on knowledge of material density. Work continues into additional methods by which material shear strength profiles can be derived directly from CPT data, without the need for historical empirical relationships or snow density. If density determination, as described above, can be further refined, then an algorithm computing real-time shear strength data during CPT may be feasible.

Relative microstructure. In examining CPT tip resistance and sleeve-friction data, McCallum (2014b) postulated that in snow of the same density, as the level of bonding increases the friction ratio should deviate; tip resistance will increase because more bonds need to be fractured whereas sleeve friction should not deviate substantially, because the mass of compacted snow remains the same. The friction ratio should therefore decrease as the amount of bonding increases. Preliminary investigation identified variation in friction ratio with snow microstructure; however, more testing is required to better quantify the relationship.

Extensive work has been conducted assessing these physical properties (and others) in alpine snow using other instruments, such as the SMP. However, CPT is the only penetrative technique known to have been successfully used in frozen geomaterials that incorporates a friction sleeve and can penetrate to substantial depth $(\sim 10 \mathrm{~m})$ at a constant rate. For this reason, references pertaining to the SMP are not considered further here. The CPT is a unique test, and references outlined herein encapsulate the complete body of work to this time.

To summarize, by using CPT in frozen geomaterials:

medium density can probably be obtained from variation in sleeve friction, $f_{\mathrm{s}}$,

medium shear strength can probably be directly derived from tip resistance $\left(q_{\mathrm{c}}\right)$ data, and

relative medium microstructure can be obtained from variation in the friction ratio, $R_{\mathrm{f}}$.

Work continues to refine these relationships. Additional parameters that can possibly be derived include:

Elastic modulus. McCallum (2012) examined the direct determination of an effective elastic modulus for snow directly from CPT data, based on the definition of Young's modulus as the ratio of uniaxial stress over 
uniaxial strain. Because snow strength can probably be estimated directly from CPT data and the failure strain for ice undergoing brittle compressive failure is $\sim 0.003$ (Schulson and Duval, 2009) then sufficient information can be obtained to generate a profile of effective elastic modulus from CPT data. Figure 10 shows representative effective modulus data from CPT conducted to $5 \mathrm{~m}$ depth in firn on the Brunt Ice Shelf, Antarctica, in 2010.

Values of effective elastic modulus extracted from Figure 10, at depths where density is known, agree with historical values of Mellor (1975). A modulus derived from average density values by Mellor ( 130 MPa) compares well with the average modulus via CPT $(\sim 150 \mathrm{MPa})$, for snow of density $450 \mathrm{~kg} \mathrm{~m}^{-3}$. Factors which may influence this estimate for effective modulus from CPT data include rate and confinement.

Bearing capacity. McCallum (2012) wrote at length on the derivation of shallow bearing capacity for snow and frozen geomaterials directly from CPT data. This preliminary analysis was not conclusive. However, using estimates for strength and modulus, as described above, it is probable that derivation of estimated bearing capacity in both homogeneous and layered frozen geomaterials is possible using CPT data directly.

Additional information on the elastic properties of the material under investigation can also be obtained through the conduct of 'dissipation tests', where CPT is stopped at certain depths and the variation in tip resistance, sleeve friction and pore pressure are examined over time, before penetration recommences. McCallum (2012) provides a preliminary analysis of such tests in polar firn; no other such tests are known to have been conducted in frozen geomaterials.

\section{FUTURE APPLICATIONS}

CPT has only limited contemporary use and interpretation in frozen geomaterials, as described above. However, its extensive historical use in testing soils means that many applications and adaptations have already been proven in non-frozen geomaterials. It is expected that most of these applications can be directly translated to use in frozen geomaterials, potentially providing extensive additional insight through the conduct of one test. Additional parameters or data that may be obtainable in the future, either from CPT or via additional instrumentation added to the rod string, include:

Seismic data. Seismic cones can be used in conjunction with standard CPT equipment to derive the velocity of $\mathrm{p}$ and s-waves within the material, thus assisting in the estimation of the dynamic elastic modulus (Lunne and others, 1997), which is of benefit in estimating vertical stresses under surface loading and the subsequent bearing capacity of the material.

Visual data. A video cone can be used in conjunction with standard CPT to observe stratigraphy/microstructure. Hawley (2005) has investigated the use of a borehole video camera to measure vertical strain within a snowpack, and a video cone might allow similar interrogation in addition to the assessment of standard CPT parameters.

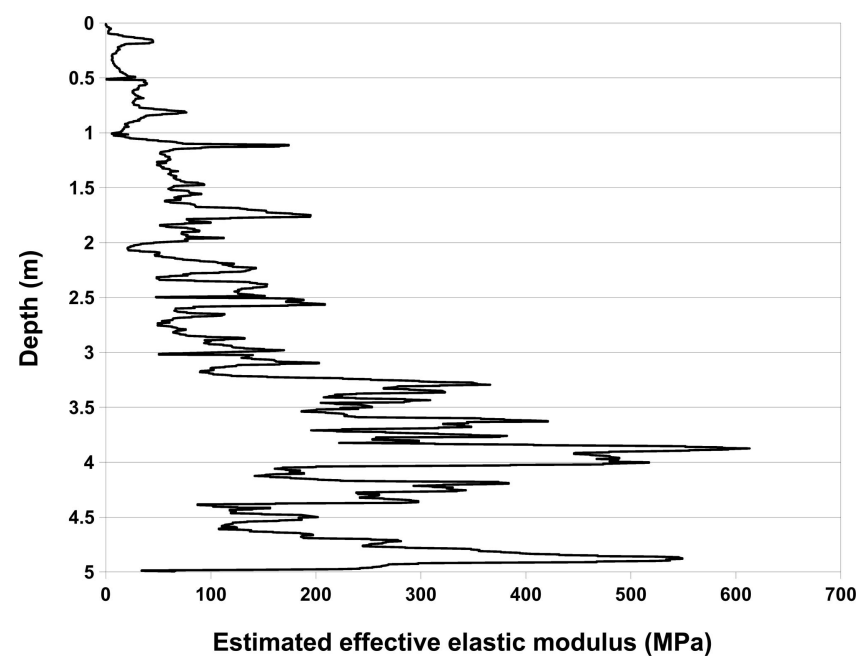

Fig. 10. Possible variation of effective elastic modulus with depth, obtained from CPT tip resistance data.

Environmental contaminants. Laser-induced florescence, an in situ spectroscopy tool (Dietrich and Leven, 2009), can be used with CPT for the detection of hydrocarbons by fluorescence. Fluorescence intensity is proportional to petroleum hydrocarbon concentration, and a detailed three-dimensional map of the non-aqueous phase liquid distribution can be generated in real time as spatial testing continues.

Nuclear density data. A nuclear density module could be added to the rod string to provide additional medium density information while conducting CPT. This would provide data similar to those obtained from the neutron probe (Morris and Cooper, 2003).

Pore-pressure data. The cones used by McCallum (2012) were fitted with pore-pressure sensors. However, no free water was encountered in the polar firn, hence porepressure data were not collected. A piezo-cone could be used in non-dry frozen geomaterials to aid in interpreting water content and location of free water. Additionally, via recalibration of the pore-pressure sensor, the pore air pressure could be assessed while penetrating frozen geomaterials.

Additionally, McCallum (2012) conducted a preliminary examination of the relationship between cone tip resistance and ground-penetrating radar (GPR) signal amplitude, and work continues into refining this relationship so spatial extrapolation of CPT data can occur using GPR.

There is enormous scope for continued utilization of CPT for engineering-site investigations and for scientific studies in frozen geomaterials. Although typical CPT equipment is necessarily cumbersome, through the use of screw anchors, water ballast or other innovative loading arrangements, the development of air-transportable, skidoo-mounted CPT rigs for deep field site investigation across Antarctica and the Arctic appears feasible, allowing the rapid attainment of numerous medium physical properties to depths of $10 \mathrm{~m}$ or more.

\section{CONCLUSION}

The cone penetration test is a proven technology that has been widely used and studied in soil. Although it has been 
used historically across a wide range of frozen geomaterials, its consistent contemporary use in examining physical properties of frozen geomaterials is limited. This paper has briefly examined the historical and contemporary use of CPT in frozen geomaterials, and presented some of the typical and possible information that may be obtained from such testing. Frozen geomaterials have long been studied using penetrometers; however, the incorporation of a friction sleeve in a standard CPT cone enables extraction of more physical data than obtained via probes without a friction sleeve. The number of additional sensors that can be added to a CPT rod string is constantly growing and CPT is a valuable tool for shallow physical assessment of frozen geomaterials.

\section{ACKNOWLEDGEMENTS}

McCallum's research described in this paper was possible due to the generous assistance of Lankelma and Gardline Geosciences and the British Antarctic Survey, both in Cambridge, UK, and Halley Research Station, Antarctica. Additional financial support was received from the Menzies Foundation.

\section{REFERENCES}

Abele G (1963) A correlation of unconfined compressive strength and ram hardness of processed snow. CRREL Tech. Rep. 85

Abele G (1990) Snow roads and runways. CRREL Monogr. 90-3

Bradley CC (1968) The resistograph and the compressive strength of snow. J. Glaciol., 7(51), 499-506

Brouwer JJM (2007) In-situ soil testing: guide to CPT. Lankelma, Rye Brown RL and Birkeland KW (1990) A comparison of the digital resistograph with the ram penetrometer. In ISSW' 90 . A Merging of Theory and Practice. International Snow Science Workshop, 9-13 October 1990, Bigfork, Montana. International Snow Science Workshop, Bigfork, MT, 19-30

Buteau S, Fortier R and Allard M (2005) Rate-controlled cone penetration tests in permafrost. Can. Geotech. J., 42(1), 184-197 (doi: 10.1139/t04-093)

Dietrich P and Leven C (2009) Direct push-technologies. In Kirsch R ed. Groundwater physics: a tool for hydrogeology. Springer, Berlin, 347-366

Dowd T and Brown RL (1986) A new instrument for determining strength profiles in snow cover. J. Glaciol., 32(111), 299-301

Floyer JA (2006) An update on digital penetrometer technology. Avalanche. ca, 79(06-07), 53-55

Floyer J and Jamieson B (2006) Empirical analysis of snow deformation below penetrometer tips. In Gleason JA ed. Proceedings of the International Snow Science Workshop, 1-6 October 2006, Telluride, CO. International Snow Science Workshops, Telluride, CO, 555-561

Fukue M (1977) Mechanical performance of snow under loading. (PhD thesis, McGill University)

Haefeli R (1936) Beitr. Geol. Schweiz. Geotech. Ser. Hydrol. Lieferung 3.

Hawley RL (2005) Borehole investigations of firn processes. (PhD thesis, University of Washington)

Isaev ON, Shrarev VV, Konstantinov CM, Tichomirov CM and Sadovsky AV (1995) The progress of the method of static sounding in the investigation of geotechnical properties of frozen soils. In Proceedings of the International Symposium on Cone Penetration Testing, CPT'95, 4-5 October 1995, Linköping, Sweden. (Report 3:95) Swedish Geotechnical Society, Göteborg, 179-186

Johnson JB and Schneebeli M (1999) Characterizing the microstructural and micromechanical properties of snow. Cold Reg.
Sci. Technol., 30(1-3), 91-100 (doi: 10.1016/S0165-232X(99) 00013-0)

Kronholm K (2004) Spatial variability of snow mechanical properties with regard to avalanche formation. (PhD thesis, University of Zürich)

Ladanyi B (1976) Use of the static penetration test in frozen soils. Can. Geotech. J., 13(2), 95-110

Ladanyi B (1985) Use of the cone penetration test for the design of piles in permafrost. J. Energ. Resour. Technol., 107(2), 183-187 (doi: 10.1115/1.3231174)

Ladanyi B (1992) Borehole penetration and expansion devices for ice testing. In Proceedings of the 11th International Symposium on Ice (IAHR 92), 15-19 June 1992, Banff, Alberta, Canada. International Association for Hydraulic Research, Edmonton, 773-786

Ladanyi B (1996) Borehole penetration and expansion devices for ice testing. Can. J. Civil Eng., 23(1), 157-164 (doi: 10.1139/196-016)

Ladanyi B (2000) Performance of field tests in permafrost and their use in design. In Senneset K ed. Proceedings of the International Workshop on Permafrost Engineering, 18-21 June 2000, Longyearbyen, Svalbard, Norway. Tapir Trykkeri, Trondheim, 73-94 (http://www.polymtl.ca/cgm/coord_bottin/profils/details/php? NoProf $=61$ \&showtab=PUB)

Ladanyi B, Steel A, Winsor WD and Clark JI (1991) Comparison of three methods for in situ ice strength determination. In Proceedings of the 11th International Conference on Port and Ocean Engineering under Arctic Conditions (POAC '91) 24-28 September 1991, St John's, Canada. Ocean Engineering Research Centre, Memorial University of Newfoundland, St John's, Nfld, 344-365 (http://trove.nla.gov.au/work/ 34526899? selectedversion $=$ NBD8761081)

Lunne T, Powell JJM and Robertson PK (1997) Cone penetration testing in geotechnical practice. Blackie Academic and Professional, London

Mackenzie R and Payten W (2002) A portable, variable-speed penetrometer for snow pit evaluation. In Stevens JR ed. Proceedings of the International Snow Science Workshop, 29 September-4 October 2002, Penticton, British Columbia. Snow Avalanche Programs, British Columbia Ministry of Transportation, Victoria, BC, 294-300

McCallum AB (2012) Cone penetration testing in polar snow. (PhD thesis, University of Cambridge)

McCallum A (2014a) Cone penetration testing (CPT) in Antarctic firn: an introduction to interpretation. J. Glaciol., 60(219), 83-93 (doi: 10.3189/2014JoG12J214)

McCallum AB (2014b) Cone Penetration Testing (CPT): a valuable tool for investigating polar snow. J. Hydrol. (NZ) , 52(2), 97-113

McCallum AB (2014c) Direct estimation of snow density using CPT. In Proceedings of the 3rd International Symposium on Cone Penetration Testing, 12-14 May, Las Vegas, NV, USA (http:// www.cpt14.com/cpt14-papers)

McCallum AB, Barwise A and Santos RS (2014) Is the Cone Penetration Test (CPT) useful for Arctic site investigation? In Proceedings of the ASME 33rd International Conference on Ocean, Offshore and Arctic Engineering (OMAE 2014), 8-13 June 2014, San Francisco, CA, USA

Mellor M (1975) A review of basic snow mechanics. IAHS Publ. 114 (Symposium at Grindelwald 1974 - Snow Mechanics), 251-291

Morris EM and Cooper JD (2003) Density measurements in ice boreholes using neutron scattering. J. Glaciol., 49(167), 599-604 (doi: 10.3189/172756503781830403)

Schaap LHJ and Föhn PMB (1987) Cone penetration testing in snow. Can. Geotech. J., 24(3), 335-341 (doi: 10.1139/t87-044)

Schneebeli M and Johnson JB (1998) A constant-speed penetrometer for high-resolution snow stratigraphy. Ann. Glaciol., 26 107-111

Schulson EM and Duval P (2009) Creep and fracture of ice. Cambridge University Press, Cambridge 